\title{
Competição Eleitoral Municipal: influência da fórmula eleitoral nas disputas ao cargo de prefeito em 2008 e $2012^{1}$
}

\author{
Municipal Election Competition: influence of the \\ electoral formula in disputes for the office of \\ Mayor in 2008 and 2012
}

\section{Bruno da Silva Conceição*1}

Palavras-chave

Sistema eleitoral; Competição eleitoral; Eleições.
Resumo: Neste estudo investigamos o efeito da fórmula eleitoral na competição eleitoral no Brasil, mais precisamente, nas eleições para o cargo de Prefeito em 2008 e 2012. Utilizamos o conceito de competição eleitoral que corresponde ao número de candidatos efetivos concorrendo em cada pleito. Para medir isso, recorremos ao número de candidatos efetivos (NCE), índice que estabelece o número efetivo de candidaturas que tem peso em uma disputa eleitoral. Nosso questionamento norteador é saber se haveria diferenciação na competição política nas cidades com turno único que utilizam a fórmula de plurality (maioria simples), comparada com aquelas cidades que possuem a possibilidade de segundo turno que utilizam a fórmula de majority runoff (maioria absoluta). Nosso objetivo é testar as Leis de Duverger, que indicam que quando é utilizada a fórmula de plurality tendemos para bicandidaturas, enquanto ao utilizarmos a fórmula de majority runoff tendemos para multicandidaturas na disputa majoritária. Essa tarefa será realizada pela análise comparada das competições municipais, em todas as cidades brasileiras, através dos dados provenientes do Tribunal Superior Eleitoral (TSE) que mantém os resultados das eleições gerais no país.

\footnotetext{
${ }^{1}$ Recebido em 28/02/2014 e aceito para publicação em 02/02/2015.

*1 Mestre em Ciência Política pela Universidade Federal do Rio Grande do Sul (UFRGS). Atualmente é doutorando na mesma instituição. E-mail: brunopolitica@gmail.com.
} 
Keywords: Abstract: In this research, we investigate the effect of the Electoral sistem; Electoral Competition; electoral formula in the electoral competition held in Brazil, more precisely, in the elections for the office of Mayor in Elections. 2008 and 2012. We utilize the concept of electoral competition, which corresponds to the number of effective candidates disputing in each election. To measure this, we resort to the number of effective candidates (ENC), an index that establishes the effective number of applications that have weight in an electoral contest. Our guiding questioning is to know if there would be differentiation in political competition in cities with a single round which utilize the plurality method (simple majority), compared to those cities that have the runoff possibility using the majority runoff system (absolute majority). Our objective is to test the Laws of Duverger which indicates that when the plurality method is utilized we tend to a two-party system, whilst when we utilize the majority runoff system we tend to multipartism in the majority dispute. This task will be performed by the comparative analysis of the municipal competitions in all Brazilian cities, using data from the Tribunal Superior Eleitoral (TSE) that holds the results of the general elections in the country.

\section{Introdução}

O presente artigo põe em pauta uma discussão recorrente na academia, na opinião pública, e também na população em geral, de que existem partidos "demais" no nosso cenário político e de que eles atrapalham a identificação do eleitor com seus representantes. Num certo ponto, os dados obtidos neste estudo apontam para uma efetiva caracterização do que cientistas políticos vêm defendendo ao longo do tempo, isso é: dependendo da fórmula eleitoral aplicada para regrar a competição eleitoral, temos um aumento ou uma diminuição dos partidos em competição.

Tal constatação está distanciada da visão da opinião pública de que o sistema partidário é caótico e inflado de siglas partidárias atrapalhando o andamento político. Pelo contrário, a fórmula eleitoral determina que as disputas ao Executivo municipal tenham sentidos inclusivos ou excludentes de competidores, a partir da possibilidade, ou não, de uma segunda rodada de disputa ao cargo majoritário.

Tendo em vista o acima exposto, investigamos aqui o efeito das regras institucionais no sistema partidário municipal brasileiro, nas eleições para o cargo de Prefeito em 2008 e em 2012. O intuito é determinar se a competição eleitoral segue as predições feitas por Maurice Duverger (1970), conhecidas 
como leis, segundo as quais a regra de plurality (maioria simples) tende a um dualismo de forças, enquanto a regra de majority runoff (maioria absoluta) favorece um aumento no número de competidores ao Executivo municipal.

As hipóteses trabalhadas aqui são: a fórmula eleitoral de plurality nas eleições de turno único conduz a um dualismo de forças em disputa, sendo um forte redutor da competição. E, de outro lado, a fórmula eleitoral de majority runoff nas eleições com dois turnos tende realmente a um aumento no número efetivo de candidaturas.

Após essa apresentação sucinta da problemática, abordamos como se estrutura esse artigo. Na primeira seção, abordamos o conceito de competição eleitoral e as concepções acerca da influência do sistema eleitoral na competição eleitoral. Depois, apresentamos a metodologia e detalhamos o objeto de pesquisa. Na última seção, discutimos os resultados da análise comparativa da fórmula eleitoral nas duas eleições pesquisadas neste estudo. Por fim, apresentamos as considerações finais da pesquisa e indicamos possíveis caminhos a serem explorados pelos pesquisadores do sistema eleitoral.

\section{O campo de pesquisa sobre Sistema Eleitoral}

A área de estudos sobre sistema eleitoral é prolífera em trabalhos que almejam relacionar os efeitos das regras eleitorais aos sistemas partidários (NOHLEN, 1995; NICOLAU, 1996; LIMA JR, 1997; TAVARES, 1997; COX, 1997; MAINWARING, 2001; LIJPHART, 2008; MARENCO, 2012). No pano de fundo destas pesquisas está a discussão da validade teórica das duas famosas proposições de Maurice Duverger (1970):

1. O sistema majoritário de turno único (plurality ou maioria simples) tende ao dualismo de partidos;

2. O sistema majoritário de dois turnos (majority runoff ou maioria absoluta), assim como a representação proporcional, tende ao multipartidarismo.

O teste empírico dessas leis aconteceu em duas vertentes: primeiramente, um foco nas eleições parlamentares, com análises voltadas para o cálculo de partidos efetivos nos legislativos nacionais, buscando perceber se os efeitos da configuração partidária com a adoção da plurality em distritos uninominais induzem ao bipartidarismo, e se os efeitos da representação proporcional em distritos plurinominais favorecem o multipartidarismo. A segunda vertente está direcionada para as eleições para o Executivo, principalmente as presidenciais, 
buscando testar os efeitos da competição eleitoral com maioria simples ou maioria absoluta. Nosso estudo integra-se nessa última vertente.

A competição eleitoral, conforme aqui entendida, está pautada na forma de disputa da classe política, inserida no modo de seleção de governantes da democracia representativa, que busca a prevalência do voto popular para controlar o aparato público (SCHUMPETER, 1961). Assim, o conceito de competição eleitoral está conectado à luta entre elites políticas que devem se adaptar às regras eleitorais na busca dos cargos públicos.

No Brasil, possuímos uma quantidade razoável de siglas partidárias concorrendo ao poder Executivo, nas suas variadas esferas, no período eleitoral. Nessa competição aos postos de gestão da administração pública, a influência das regras eleitorais na composição das disputas majoritárias aparece como obstáculo, ou mesmo freio, à participação de algumas candidaturas nas eleições (DUVERGER, 1970; COX, 1997). Desse modo, o sistema eleitoral torna-se uma variável importante para as decisões políticas.

Tais regras podem favorecer grandes partidos, propiciando a manutenção do status quo político, ou ainda ser mais permissivas, permitindo que novos competidores adentrem na arena eleitoral. Essa balança inclusiva ou exclusiva depende da percepção que as lideranças partidárias possuem do sistema eleitoral. Matthew Shugart e John Carey (1992) afirmam que a diferença básica entre a fórmula de plurality (maioria simples) e a fórmula de majority runoff (maioria absoluta) para a ação das lideranças partidárias é o timing em que são feitas as barganhas políticas.

To maximize their chances of victory, party leaders contesting a plurality presidential election in a multiparty environment must seek to build coalitions before the election. In most cases this means that the principal contenders will be two relatively moderate candidates. On the other hand, because majority runoff leaves much of the bargaining among parties to the period between rounds, the efficiency of presidential election is reduced. (SHUGART; CAREY, 1992, p. 216). Grifo no original ${ }^{2}$.

Essa percepção das chances de sucesso conforme a fórmula eleitoral vigente pode passar despercebida na maioria dos pequenos partidos. Continuam existindo partidos eleitorais lançando candidaturas em contextos menos favoráveis de sucesso, segundo os dados apurados nesta pesquisa.

\footnotetext{
2 Para maximizar suas chances de vitória, os líderes partidários que disputam a eleição presidencial em maioria simples em um ambiente multipartidário devem procurar construir coalizões antes da eleição. Na maioria dos casos, isto significa que os principais competidores serão dois candidatos relativamente moderados. Por outro lado, por causa da maioria absoluta conduzir muito da negociação entre os partidos para o período entre os turnos, a eficiência da eleição presidencial é reduzida. (tradução minha, grifo no original)
}

Caderno eletrônico de Ciências Sociais, Vitória, v. 2, n. 2, p. 34-55. 
Talvez a visibilidade que a campanha eleitoral traz ao partido e ao candidato seja uma estratégia bastante vantajosa pensando no futuro da carreira política do candidato e mesmo mesmo nas alianças do partido. Todavia, os custos dessa falta de informação acerca do timing correto para se levar em frente uma candidatura podem acarretar perda posterior de espaço na formação das coalizões de governo. É provável que partidos que aderem mais cedo a um competidor vencedor terão uma maior fatia no "bolo" do governo, seja em postos da administração pública ou em cargos comissionados.

Antes de encerrarmos essa seção, são necessários alguns apontamentos sobre a agenda de pesquisa que critica a relevância do argumento de que o sistema eleitoral influencia o subsistema partidário, antagônica ao caminho proposto aqui de utilizar a abordagem de Duverger (1970). Segundo Juan Rial (1988), vários autores vêm discutindo, ao longo do tempo, uma inversão na direção da causalidade sendo o sistema partidário a influenciar o sistema eleitoral, já que é a classe política quem determina as "regras do jogo". Desse modo, um recorte que investigue as negociações interpartidárias feitas pelas lideranças políticas das siglas seria mais prolífero em explicações sobre como funciona a democracia representativa, restando ao sistema eleitoral o papel de consolidar as diretrizes feitas pela elite política.

O temor sentido por certos líderes da falta de apoio popular suficiente para adotar regras que Ihes favoreçam, de maneira irrestrita, termina por conduzir a uma opção de sistema eleitoral permissivo que diminuam as chances de alguns atores políticos serem "perdedores absolutos" (COLOMER, 2003). Seguindo a argumentação de Downs (1999) sobre a incerteza, sobre quais aspectos seriam mais atrativos para o eleitor tomar sua decisão em quem votar, seria custoso adotar um sistema eleitoral que beneficie uma minoria, pois a obrigação de fazer um bom governo aumenta.

Outra decorrência da decisão por um sistema eleitoral rígido seria que uma alternância do poder indicaria custos muito altos de o partido antecessor retomar o poder futuramente. "Cabe, pues, esperar que solamente en situaciones en las que haya un solo partido que sea institucionalmente dominante y espere obtener o mantener un amplio apoyo de los votantes se elegirán 0 mantendrán reglas restrictivas basadas en requerimientos de mayoría" (COLOMER, 2003, p. 41).

Essa opção interesseira das lideranças políticas vista por Colomer (2003) esbarra em uma constatação clara das teorias de transição democrática de que a abertura para competição partidária é um pressuposto da democracia representativa. Desta forma, é esperada a possibilidade de haver alternância com o lado perdedor aceitando uma eventual derrota. Afirmar que a regra de maioria é limitadora da competição eleitoral, por favorecer apenas um ganhador, é uma verdade apenas parcial. Afinal, em países que utilizam a 
plurality, tanto para o Executivo quanto para o Legislativo, isso não impediu o surgimento de uma terceira força política (Reino Unido), e nem causou um monopólio partidário (Estados Unidos da América).

O problema em argumentar que a condição das regras está sujeita ao número de partidos existentes reside no erro em aproximar os partidos eleitorais dos partidos efetivos, aqueles que realmente fazem a diferença. $O$ acordo sobre qual sistema eleitoral deve ser adotado presume cessões de espaço para minorias. Sistemas eleitorais mais pluralistas impediriam que minorias, antes excluídas do processo decisório, terminem por utilizar a força para depor seus antigos opressores (BOIX, 2003).

Gary Cox (1997) defende que, apesar da incerteza da direção da causalidade - qual variável é causal e qual é causada -, para obterem sucesso, é fundamental que as lideranças partidárias saibam coordenar suas estratégias de maximização de sufrágios, ou mesmo de ganhos políticos materiais. Para isso, as elites precisam se adaptar às regras eleitorais existentes para se beneficiarem delas. Nessa perspectiva, conhecer o timing para lançar uma candidatura, desistir dela, ou fazer uma coalizão torna-se um requisito indispensável para o sucesso eleitoral.

Focando em vários casos pelo mundo afora, os sistemas eleitorais de alguns países combinam regras de maioria com representação proporcional, como é o caso brasileiro, cabendo aos partidos fazerem coalizões ou lançarem candidaturas isoladas, dependendo da disputa em questão. No que tange a obtenção de cargos, o Executivo parece mais restritivo, conforme os dados desta pesquisa, enquanto o Legislativo, com a adoção da representação proporcional, fornece maiores dividendos aos partidos, porque a magnitude dos distritos é maior que $M=1$ na maioria dos sistemas partidários (NOHLEN, 1995). O fato é que, se fosse irrelevante o sistema eleitoral na vida partidária, os cálculos estratégicos de tempo de campanha, alianças, etc. seriam desperdício de recursos.

\section{Consequências da Fórmula Eleitoral na Competição Política}

Como mencionado anteriormente, Maurice Duverger (1970) foi pioneiro a observar os efeitos do sistema eleitoral sobre o sistema partidário. Duas leis foram elaboradas pelo cientista político francês para dar conta desse fenômeno. A primeira lei prevê que quando há um escrutínio majoritário de turno único, as legendas teriam reduzidas suas expectativas de sucesso no pleito, pela regra da maioria simples, para aprovação de um novo governo, tendendo a levar, na prática, ao bipartidarismo: "Os métodos de maioria simples (plurality) em distrito uninominal são do tipo 'o vencedor leva tudo': vencem os candidatos apoiados pelo maior número de eleitores, e todos os demais ficam sem representante - o que reflete perfeitamente a filosofia majoritária." (LIJPHART,

Caderno eletrônico de Ciências Sociais, Vitória, v. 2, n. 2, p. 34-55. 
2008, p.169). O exemplo típico é o bipartidarismo norte-americano que, através de suas regras eleitorais, termina por limitar a disputa entre o Partido Republicano e o Partido Democrata.

O efeito derivado das regras coercitivas, adotadas em sistemas partidários majoritários de turno único, produz dois tipos de fatores: de um lado, o fator mecânico que amparado na regra eleitoral força uma subrepresentação da terceira força política, e, de outro lado, o fator psicológico, atuando no eleitor, que retira votos dessa terceira força partidária. Os fatores mecânicos e psicológicos beneficiam os grandes partidos ao induzirem os eleitores, pelo temor de desperdiçar seu voto, a selecionar sua segunda preferência partidária, com potenciais chances de sucesso no pleito, como opção na cabine de votação (DUVERGER, 1970).

Essa convergência entre a fórmula eleitoral da maioria simples e os efeitos mecânicos e psicológicos elencados por Duverger (1970) caracteriza uma forte barreira para ascensão de novos partidos. "Uma proposição da análise política comparada que se tornou muito conhecida é a de que o método da maioria simples favorece os sistemas bipartidários" (LIJPHART, 2008, p.189).

Sobre a segunda lei de Duverger, ela já prega uma lógica inversa. Quando há um escrutínio majoritário de dois turnos tende-se a um aumento dos competidores, uma vez que há uma primeira rodada de competição, com vários partidos, entre os quais, se nenhum obtiver a metade mais um dos votos, os dois mais votados serão selecionados para a rodada final - o segundo turno. "De fato, a ação do sistema de escrutínio poderia ser comparado à de um freio ou de um acelerador." (DUVERGER, 1970, p.241). Quando não temos um franco favorito, que vença já no primeiro turno, prospera um cenário de incerteza sobre quem passará para o segundo turno, incentivando o lançamento de um maior número de candidaturas para o Executivo.

$\mathrm{Na}$ ótica dos partidos, eles necessitam posicionar-se conforme as regras do jogo de maneira pragmática no intuito de maximizar suas chances de arrecadação de sufrágios (COX, 1997; DOWNS, 1999). Os candidatos teriam incentivos, na rodada inicial, para apresentar seus programas partidários, suas posições no que tange a assuntos cotidianos ou problemas frequentes do município, etc. Selecionados os postulantes ao cargo do Executivo, na rodada final interessa consolidar seu projeto de governo no imaginário da população. Aquele candidato mais votado no primeiro turno tenta manter ou ampliar sua votação, enquanto o segundo colocado almeja uma ultrapassagem final, tentando maximizar os votos dos indecisos e dos candidatos perdedores do primeiro turno.

As condições que propiciam tanto o multipartidarismo quanto o bipartidarismo estão dadas acima. O multipartidarismo é esperado quando há 
uma fórmula eleitoral menos restritiva sobre as regras do jogo, ou seja, quando há a possibilidade de segundo turno. O bipartidarismo é esperado quando há de uma fórmula eleitoral mais restritiva, por exemplo, pela ausência de uma rodada extra, para aqueles que não atingem $50 \%$ mais 1 dos votos válidos, que é o caso da maioria das eleições para Prefeituras analisadas nesta pesquisa.

Nossa pesquisa aborda esse fenômeno do bipartidarismo a partir da perspectiva proposta por Gary Cox (1997) quanto ao número de candidatos ou candidaturas efetivos na disputa eleitoral. Essa adaptação proposta por Cox (1997) serve para testarmos as leis de Duverger para o caso nacional. Preferimos, então, centrar nas candidaturas, que até podem agregar um combinado de siglas em apoio a uma candidatura, para testar as hipóteses de pesquisa com as seguintes terminologias: candidato dominante, bicandidaturas (para dualismos na competição eleitoral), e multicandidaturas (para casos de mais de dois candidatos).

\section{Aspectos Metodológicos}

A metodologia adotada será a de separar os municípios com segundo turno daquelas localidades com turno único para analisar os efeitos das leis de Duverger quanto à fórmula eleitoral: plurality e majority runoff. Vários autores salientam que a comparação é o meio aproximado mais eficiente de controlarmos nossas hipóteses de pesquisa (SARTORI, 1994; PANEBIANCO, 1994; MORLINO, 1994; KEMAN, 2008). Para tanto, precisamos ter cuidado na seleção de casos que se enquadrem em duas lógicas básicas: 1) não sejam completamente idênticos; 2) não sejam absurdamente diferentes.

O teste da consistência das leis de Duverger será feito através de um índice amplamente utilizado na Ciência Política. O índice do número de partidos efetivos (NPE), criado por Markku Laakso e Rein Taagepera (1979), serve para visualizar quantos partidos, de fato, tem peso/poder em uma instância representativa para formação de maiorias e, consequentemente, viabilizar ou impedir decisões na instância representativa (NICOLAU, 1997).

Neste caso, no entanto, será feito um ajuste para medir o número efetivo de candidaturas ${ }^{3}$, ao invés do número efetivo de partidos, devido à formação de coligações nas disputas majoritárias acontecerem de maneira corrente. Esse é um forte impeditivo para calcularmos bipartidarismo para o Executivo (NICOLAU, 1996; TAVARES, 1997).

\footnotetext{
${ }^{3}$ Gary Cox (1997) utiliza a nomenclatura Number of Viable Competitors para analisar a competição eleitoral nas eleições majoritárias. É a mesma fórmula de Laakso e Taagepera (1979) aplicando o cálculo a percentagem de votos dos candidatos. Utilizaremos a expressão Número de Candidatos Efetivos (NCE) para facilitar a compreensão, porém é o mesmo sentido usado por Cox (1997). A fórmula é $\mathbf{N}=\mathbf{1} / \mathbf{\Sigma}(\mathbf{V i} / \mathbf{1 0 0})^{2}$ Onde: $\mathrm{Vi}=$ percentagem de votos de cada candidato.
} 
Sendo raro acontecer uma disputa majoritária entre somente dois partidos é necessário fazer uma adequação. O desvio do objeto de análise dos partidos para os candidatos, ou candidaturas lançadas por eles de maneira isolada ou conjunta, parece ser o modo mais adequado de mensuração do fenômeno da competição eleitoral no caso brasileiro. O foco nas candidaturas é uma ferramenta heurística já utilizada para esses casos de competição eleitoral ao Executivo (SHUGART; CAREY, 1992, COX, 1997).

Esse recorte facilita determinar possíveis discrepâncias nas poucas, porém centrais, localidades do país que, em razão de possuírem mais de 200 mil eleitores, adotam o $2^{\circ}$ turno, caso não haja um vencedor por maioria absoluta de votos no $1^{\circ}$ turno. Os dados analisados serão provenientes das estatísticas do Tribunal Superior Eleitoral (TSE), que mantém os resultados das eleições gerais no país.

\section{Por que analisar o local?}

Cada município é um caso diferenciado? Aspectos cotidianos de cada localidade influenciam diretamente uma eleição? Seria problemático levar em frente esta pesquisa seguindo à risca a perspectiva de que os efeitos dos fatores ambientais locais superam os das normas que regem a competição eleitoral. Por mais discrepantes que sejam os dilemas enfrentados por eleitores do Norte, do Nordeste do país, se comparado aos dilemas dos moradores da região Sul ou Sudeste, presumimos haver um elo causal comum aos diversos municípios, apesar da mudança de sotaques, de qualquer classe política frente ao seu eleitorado no país: a busca pela eleição (DOWNS, 1999; MAINWARING, 2001).

Pautando-se na questão da eleição, Scott Mainwaring (2001) percebe um incentivo para a busca ou a perpetuação no cargo público local, pois "para ter poder no partido nacional, é preciso ser poderoso em seu próprio estado de origem. A carreira dos políticos brasileiros depende em grande medida do que acontece no nível local" (MAINWARING, 2001, p.309). Nossa ênfase, posta na influencia das regras institucionais, não invalida pesquisas que busquem saber mais detalhadamente sobre uma região ou local específico. Uma visão antropológica da política está servindo para elucidar pontos cruciais da dinâmica local entre representante e representado. A limitação está na capacidade de generalização dessas descobertas para outros contextos.

As evidências empíricas que a análise de eleições locais fornece aos testes de conjecturas teóricas é algo a ser ressaltado, uma vez que os resultados obtidos na esfera local podem corroborar ou refutar evidências encontradas na esfera nacional (SAWICKI, 1988). Destacando os ganhos que podem ser obtidos por esse tipo de pesquisa, Cox (1997) observa que muitas das predições de 
Duverger (1970) tinham como alvo observações de dados distritais antes de inferi-las para o nível nacional.

As pesquisas sobre dados de eleições locais estão longe de serem contraditórias com as pesquisas de âmbito nacional. Entretanto, eleições locais enfrentam o estigma de serem mais pautadas pela despolitização e pelo personalismo. Os meios de comunicação, a população e os próprios políticos tendem a enxergar um desinteresse progressivo dos eleitores pela vida política (COLLOVALD; SAWICKI; HEURTIN, 1989). Pela proximidade dos prefeitos com a população, os incentivos para pedidos mais clientelistas são vistos como propícios às práticas de campanha, em parte devido ao caráter vago e casuísta das promessas eleitorais. A questão que surge desse cenário é: será que as regras de maioria, principalmente a plurality, provocam o domínio local clientelista em algumas cidades? Em outras palavras, casos de amplo domínio de famílias ou candidatos em cidades são reforçados pelo efeito de redução da competição da fórmula de turno único?

Para essas dúvidas, análises focalizadas longitudinais são de grande auxílio à elucidação. Pode-se dizer, como resposta prévia, que o distrito uninominal exerce uma forte restrição à competição eleitoral por fortalecer uma disputa dualista, atenuada se há dois turnos de disputa. Os dados da pesquisa, que veremos no próximo tópico, são expressivos dos efeitos redutores da competição eleitoral quando somente há uma vaga em disputa. "Para fazer carreira, os políticos têm de observar um grande número de regras, mas duas delas são fundamentais: o sistema eleitoral e a seleção de candidatos". (MAINWARING, 2001, p.301).

Isso acontece devido ao fator psicológico de Duverger (1970) - que possui afinidades com o conceito de voto estratégico de Cox (1997) - atuar retirando sufrágios dos candidatos mal posicionados tanto em plurality, quanto em majoritiy runoff. Os dois primeiros colocados na corrida política são beneficiados pela tentativa do eleitor de maximizar ganhos particulares apostando no candidato melhor posicionado (DOWNS, 1999). Assim, conforme a percepção que cada eleitor faz sobre os sufrágios dos outros eleitores, em conjunto com as estatísticas das pesquisas eleitorais que antecedem o pleito, o indivíduo adapta seu voto às melhores chances de seu candidato mais bem posicionado vencer (COX, 1997).

Pelo acima exposto, se nos municípios brasileiros possuímos recorrentes casos de prefeitos que estão diversas vezes concorrendo ou mesmo mantendose nos cargos, pleito após pleito, parece lógico creditarmos uma parcela de responsabilidade deste fenômeno ao sistema eleitoral. 


\section{Análise dos resultados nos municípios com plurality}

Nossa abordagem está voltada para as disputas majoritárias municipais onde a fórmula eleitoral para seleção do governante permite duas possibilidades de disputa: turno único em plurality (maioria simples) e dois turnos em majority runoff (maioria absoluta). A implantação do princípio majoritário, considerando eleições democráticas sem fraudes no Brasil, provém do Código Eleitoral de $1950^{4}$.

Em 1950, o Congresso promulgou um novo Código Eleitoral que, pela primeira vez na história da República, adotou sistemas eleitorais iguais para cargos equivalentes nos três níveis da estrutura federal: a representação proporcional para a Câmara dos Deputados, as Assembleias Legislativas e as Câmaras Municipais e a regra majoritária para a eleição de presidente, vice-presidente, governadores, vicegovernadores, prefeitos e vice-prefeitos. (NICOLAU, 2012, p. 91).

Mesmo no período de ditadura militar manteve-se no Código Eleitoral de $1965^{5}$ a realização de eleição direta para prefeito. O formato atual do sistema eleitoral surge a partir da Constituição Federal de $1988^{6}$, sendo da mesma forma observada na Lei das Eleições ${ }^{7}$ de 1997, com o prefeito elegendo-se com o maior número de votos válidos.

Cabe fazermos uma observação sobre a nomenclatura adotada, daqui pra frente, sobre a fórmula eleitoral. Para evitarmos dúvidas de interpretação, apontaremos a fórmula eleitoral na sua conceituação internacional, ou seja, plurality e majority runoff, ao invés de maioria simples e maioria absoluta, respectivamente. Isso evitará transtornos de significado ao tratarmos os dados empíricos.

Baseado no cálculo do número de candidatos efetivos (NCE) de cada cidade, uma distinção prévia é feita a partir dos valores obtidos em cada localidade. Os valores de 1,0 a 1,4 correspondem a uma eleição ganha com ampla vantagem de um candidato sobre o seu rival mais próximo. Os valores de 1,5 a 2,5 indicam uma composição dualista de força nos pleitos, ao redor de

\footnotetext{
${ }^{4}$ Lei no1164, de 24 de julho de 1950, art.46.

${ }^{5}$ Art. 83 Na eleição direta para o Senado Federal, para Prefeito e Vice- Prefeito, adotar-seá o principio majoritário. Lei no 4.737, de 15 de julho de 1965.

${ }^{6}$ Art. 29, inciso I - eleição do Prefeito, do Vice-Prefeito e dos Vereadores, para mandato de quatro anos, mediante pleito direto e simultâneo realizado em todo o País;

Art. 29, inciso II - eleição do Prefeito e do Vice-Prefeito realizada no primeiro domingo de outubro do ano anterior ao término do mandato dos que devam suceder, aplicadas as regras do art.77 no caso de Municípios com mais de duzentos mil eleitores. Constituição da República Federativa do Brasil.

7 Art. $3^{\circ}$ Será considerado eleito Prefeito o candidato que obtiver a maioria dos votos, não computados os em branco e os nulos. Lei no 9.504, de 30 de setembro de 1997.
} 
$90 \%$ dos votos válidos divididos entre dois candidatos, enquanto que valores acima de 2,5 denotam uma disputa de multicandidaturas (RAE, 1971; NOHLEN, 1995; NICOLAU, 1996).

Vistas estas definições de mensuração, passamos ao teste da primeira hipótese da pesquisa de que a fórmula eleitoral de plurality, nas eleições de turno único, conduz a um dualismo de forças em disputa, sendo um forte redutor da competição eleitoral.

$\mathrm{Na}$ maioria dos municípios brasileiros adota-se a fórmula eleitoral de plurality para a escolha dos prefeitos. A exceção ocorre nas capitais estaduais e nas cidades que possuem um eleitorado que ultrapasse os 200 mil eleitores. $\mathrm{Na}$ tabela 1, analisamos as eleições municipais de 2008 em plurality.

Tabela 1. Competição eleitoral nos Municípios por Região com plurality nas eleições de primeiro turno de 2008 (\%)

\begin{tabular}{|c|c|c|c|c|c|c|}
\hline \multirow[b]{2}{*}{ plurality } & \multicolumn{5}{|c|}{ Regiões do Brasil } & \multirow[b]{2}{*}{$\begin{array}{c}\text { Média } \\
\text { nacional }\end{array}$} \\
\hline & $\begin{array}{l}\text { Região } \\
\text { Norte }\end{array}$ & $\begin{array}{c}\text { Região } \\
\text { Nordeste }\end{array}$ & $\begin{array}{c}\text { Região } \\
\text { Centro- } \\
\text { Oeste }\end{array}$ & $\begin{array}{l}\text { Região } \\
\text { Sudeste }\end{array}$ & $\begin{array}{c}\text { Região } \\
\text { Sul }\end{array}$ & \\
\hline Candidato Dominante & 7,0 & 7,9 & 6,1 & 8 & 8,1 & 7,8 \\
\hline Bicandidaturas & 63,5 & 81,1 & 76,4 & 75,2 & 78,0 & 76,8 \\
\hline Multicandidaturas & 29,5 & 11,0 & 17,5 & 16,8 & 13,9 & 15,4 \\
\hline Total & $(441)$ & $(1777)$ & $(458)$ & $(1625)$ & $(1176)$ & 100,0 \\
\hline
\end{tabular}

Fonte: TSE, dados processados pelo autor. Cidades $\mathrm{N}=5477$.

Reunimos, na tabela 1, as cidades que na eleição de 2008 tinham como fórmula eleitoral a plurality para escolha de seu prefeito local. Nota-se, nos dados, que se somássemos os resultados nacionais de bicandidaturas em conjunto aos resultados de candidatos dominantes chegaríamos a um percentual de $84,6 \%$ de presença concentrada de dois candidatos com forte votação. Presume-se nisto a influência dos efeitos mecânicos e psicológicos, previstos por Duverger (1970), nas localidades que usam a fórmula eleitoral de plurality (NICOLAU, 1996). "A proposição de Duverger acerca da relação entre sistema de maioria simples e bipartidarismo pode ser vista como o resultado da composição dos efeitos mecânico e psicológico. Em um sistema eleitoral de maioria simples e magnitude $M=1$, os dois efeitos ocorrem basicamente no âmbito local". (NICOLAU, 1996, p.47).

$\mathrm{Na}$ tabela 2, apresentamos os dados empíricos dos municípios que utilizaram a fórmula de plurality para escolha do seu governante local na eleição de 2012. Comparando os dois pleitos visualiza-se uma simetria quanto aos percentuais de competição eleitoral. 
Tabela 2. Competição eleitoral nos Municípios por Região com plurality nas eleições de primeiro turno de 2012 (\%)

\begin{tabular}{|c|c|c|c|c|c|c|}
\hline \multirow[b]{2}{*}{ plurality } & \multicolumn{5}{|c|}{ Regiões do Brasil } & \multirow[b]{2}{*}{$\begin{array}{c}\text { Média } \\
\text { nacional }\end{array}$} \\
\hline & $\begin{array}{l}\text { Região } \\
\text { Norte }\end{array}$ & $\begin{array}{l}\text { Região } \\
\text { Nordeste }\end{array}$ & $\begin{array}{l}\text { Região } \\
\text { Centro- } \\
\text { Oeste }\end{array}$ & $\begin{array}{l}\text { Região } \\
\text { Sudeste }\end{array}$ & $\begin{array}{c}\text { Região } \\
\text { Sul }\end{array}$ & \\
\hline Candidato Dominante & 4,1 & 5,1 & 5,7 & 6,8 & 6,8 & 5,9 \\
\hline Bicandidaturas & 65,4 & 84,3 & 77,9 & 75,4 & 82,4 & 79,1 \\
\hline Multicandidaturas & 30,5 & 10,6 & 16,4 & 17,8 & 10,8 & 15,0 \\
\hline Total & $(442)$ & $(1775)$ & $(457)$ & $(1627)$ & $(1179)$ & 100,0 \\
\hline
\end{tabular}

Fonte: TSE, dados processados pelo autor. Cidades $\mathrm{N}=5480$.

O percentual da soma de resultados de candidatos dominantes e bicandidaturas, na média nacional, em 2012, chegam a $85 \%$, ou seja, resultado similar à eleição de 2008. Os dados verificados nos municípios brasileiros nestas eleições são representativos dos efeitos redutores da competitividade eleitoral, quando não há a possibilidade do segundo turno, conforme visto por Duverger (2003): "Riker's analysis confirms that the link between two-party systems and plurality voting has been observed and verified for a longer time than the others". (DUVERGER, 2003, p.70). ${ }^{8}$

Nesta situação, a solução para as lideranças partidárias dos partidos pequenos para participarem da corrida ao governo será estabelecer pactos, alianças ou coligações antes do pleito, já que os benefícios da entrada no governo após a eleição podem ser menores, resultando em influência diminuta em cargos ou ações do governo (SHUGART; CAREY, 1992).

Há, simultaneamente, o recurso do voto útil atuando para diminuir os custos de o eleitor "desperdiçar" sua escolha em um candidato com poucas chances de sucesso, escolhendo alguém mais bem posicionado nas pesquisas. Assinalado por Duverger (1970) como fator psicológico, o fenômeno é denominado por Cox (1997) como voto estratégico. Isso significa que o processo de competição dentro do mercado eleitoral é limitado tanto pelas restrições da fórmula eleitoral, quanto pela dificuldade de arrecadar investimentos para campanha nestas cidades.

Apesar de a Justiça Eleitoral brasileira fornecer espaço de exposição para as legendas no período de campanha, as discrepâncias em tempo de TV, em utilização de recursos provindos do fundo partidário e em aplicação dos gastos

\footnotetext{
${ }^{8}$ A análise de Riker confirma que o elo entre os sistemas bipartidários e votações com maioria simples tem sido observado e verificado por mais tempo do que outros (tradução minha).
} 
em marketing são empecilhos substanciais para demarcar as barreiras que além dos fatores mecânicos e psicológicos - os pequenos partidos enfrentam para concorrer na corrida eleitoral contra seus adversários.

Conforme observou Cox (1997), um eleitor que possua uma razoável informação sobre as preferências dos outros eleitores e do provável resultado final da eleição, informado pelos meios de comunicação e institutos de pesquisa, tenderá a desistir do seu candidato preferido, se esse estiver posicionado em $3^{\circ}$ lugar, para sua segunda melhor opção dentre os líderes da disputa em plurality. Então, o conjunto de fatores expostos colabora para uma forte concentração da competição numa lógica dualista em distritos uninominais de turno único.

O mérito das observações de Duverger (1970) está na pertinência de sua análise institucional sobre a competição eleitoral para a compreensão dos resultados obtidos nesta pesquisa. Verifica-se isso no embate com outra explicação possível para dar conta da causa de bicandidaturas em plurality: a abordagem sociológica.

A perspectiva sociológica fornece uma explicação contrária ao argumento de que a fórmula de plurality incentiva um dualismo na competição eleitoral. A estrutura da competição política seria derivada das clivagens existentes na sociedade que oporiam os cidadãos, ou grupos, fazendo-os escolherem lados (LIPSET; ROKKAN, 1967). Tomando o processo de reabertura democrática, de maneira arbitrária, como ponto de partida formador dos conflitos na sociedade brasileira, devido o fim da ditadura civil-militar terminar com a imposição de um bipartidarismo, esses conflitos societários emergidos do processo de reabertura política seriam mediados pelos partidos políticos, então nascentes, constituindo um arcabouço que moldaria a competição política até os dias atuais. No entanto, acreditando que os partidos estariam, em termos ideológicos, expressando as clivagens existentes nos municípios, estaríamos presos em algumas questões: as clivagens que acontecem numa região poderiam ser traduzidas para todo o país? Ou cada local possui sua especificidade de clivagens? Como imputar apenas um tipo de clivagem como base de conflito numa população tão heterogênea? Na tabela 3, apresentamos o número de candidatos lançados e eleitos em 2008 e em 2012. 
Tabela 3. Partidos que alcançaram prefeituras nas eleições de 2008 e de 2012 sob a fórmula de plurality

\begin{tabular}{|c|c|c|c|c|}
\hline \multirow[t]{2}{*}{ Partido } & \multicolumn{2}{|c|}{ Candidatos Lançados por Partido } & \multicolumn{2}{|c|}{ Eleitos por Partido } \\
\hline & 2008 & 2012 & 2008 & 2012 \\
\hline DEM & 1.234 & 728 & 495 & 273 \\
\hline PC do B & 192 & 227 & 41 & 52 \\
\hline PCB & 40 & 36 & 0 & 0 \\
\hline PCO & 9 & 5 & 0 & 0 \\
\hline PDT & 979 & 834 & 351 & 305 \\
\hline PHS & 96 & 118 & 13 & 16 \\
\hline PMDB & 2.648 & 2.254 & 1.194 & 1.018 \\
\hline PMN & 168 & 177 & 42 & 43 \\
\hline PP & 1.203 & 1.075 & 549 & 471 \\
\hline PPS & 518 & 48 & 129 & 11 \\
\hline PR & 911 & 427 & 384 & 123 \\
\hline PRB & 261 & 704 & 54 & 271 \\
\hline PRP & 91 & 300 & 17 & 79 \\
\hline PRTB & 96 & 134 & 11 & 24 \\
\hline PSB & 881 & 99 & 308 & 16 \\
\hline PSC & 248 & 1.026 & 57 & 429 \\
\hline PSDB & 1.776 & 307 & 787 & 84 \\
\hline PSDC & 92 & 1.091 & 8 & 491 \\
\hline PSL & 95 & 1.616 & 15 & 688 \\
\hline PSOL & 280 & 88 & 0 & 10 \\
\hline PSTU & 34 & 112 & 0 & 23 \\
\hline PT & 1.630 & 347 & 549 & 1 \\
\hline PT do B & 87 & 59 & 8 & 0 \\
\hline PTB & 1.004 & 1.774 & 410 & 628 \\
\hline PTC & 93 & 107 & 13 & 25 \\
\hline PTN & 96 & 817 & 16 & 297 \\
\hline PV & 380 & 90 & 75 & 19 \\
\hline Total & 15.142 & 15.091 & 5.526 & 5.506 \\
\hline
\end{tabular}

Fonte: TSE, dados processados pelo autor.

Visualizando o banco de dados do TSE das eleições de 2008 e de 2012, temos um número superior a 15.000 candidaturas lançadas, em cada eleição, sob plurality. Esse resultado denota que candidaturas estão sendo lançadas, mesmo se observarmos os fatores mecânicos e psicológicos de Duverger. Vários partidos tiveram candidatos eleitos mostrando que se as clivagens afetassem a competição eleitoral, o número de partidos com representação no Executivo deveria ser muito menor devido à consolidação das clivagens, após décadas de 
eleições (LIPSET \& ROKKAN, 1967). A consolidação, ao longo do tempo, de clivagens estruturantes parece não ter ocorrido no país.

Outro problema da abordagem sociológica parte das coligações interpartidárias no Brasil que amoldam interesses múltiplos. Como partidos que representam ideologias de setores da sociedade formam alianças, por vezes, pouco ideológicas? Essa ótica se coaduna com a constatação de Otto Kirchheimer (1966) acerca dos partidos políticos modernos, que estão perdendo seus traços programáticos e substituindo por um pragmatismo eleitoral calcado na maximização dos sufrágios dispersos na população, resultando na diluição do aspecto ideológico.

Estes são problemas sérios derivados de uma análise de casos locais cuja teoria, ajustada para casos europeus, pode não ser eficaz em responder aos vieses dos casos latino-americanos. A perspectiva de Lipset \& Rokkan (1967) pode dar conta satisfatoriamente dos casos europeus, porém, perde um pouco do seu potencial heurístico se não for adaptada à realidade empírica das realidades nacionais.

Um confronto desta perspectiva sociológica com a abordagem institucional, usando como casos países da América do Sul, foi realizado por Gary Cox (1997), que fez um teste da abordagem sociológica comparando o número de partidos eleitorais que disputaram assento legislativo nos países com duas Câmaras (Alta e Baixa). Neste teste, se os partidos correspondessem aos conflitos existentes nas sociedades em análise, eles estariam representados, em similitude, em suas respectivas proporções na Câmara Alta e na Câmara Baixa de cada país. Os resultados vistos pelo autor mostram discrepâncias no número de partidos estimados nas duas casas em $90 \%$ dos casos. Esse teste feito por Cox (1997) foge da temática dessa pesquisa, que focaliza eleições majoritárias, porém ajuda a combater a visão de que o sistema eleitoral tem pouca importância.

Sabemos de antemão que os partidos são os grupos que deveriam assimilar o conflito existente na sociedade. Dessa forma, o foco de análise da perspectiva sociológica se direciona para os partidos no que concerne à competição. Foco que revela seus limites interpretativos para a significativa ocorrência de sistemas bipartidários em sociedades complexas (TAVARES, 1997). Assim, o sistema eleitoral permanece como uma variável convincente para explicar a competição política. Além do mais, tendo sido inicialmente voltada para casos europeus, sua aplicabilidade em terras tão distantes mostra uma vitalidade da teoria de Duverger (1970), que deve ser mais explorada. Na próxima seção, veremos que os resultados eleitorais dos municípios com majority runoff diferem dos encontrados em plurality. 


\section{Análise dos resultados nos municípios com majority runoff}

Neste instante, partimos para os resultados eleitorais nas localidades que podem exigir uma segunda rodada de disputa. Assim, podemos comparar se os efeitos vistos em plurality, os efeitos mecânico e psicológico que reduzem o número efetivo de candidatos a um dualismo, acaba mesmo perdendo sua eficácia em majority runoff (DUVERGER, 1970).

Maurice Duverger (1970) reúne dados de vários países europeus, da primeira metade do século $X X$, onde a associação entre segundo turno e multipartidarismo é muito forte, confirmando sua predição. "Em suma, as diferenças no número e na permanência de partidos, em sistema majoritário de dois turnos, parecem vir muito mais de fatores nacionais particulares do que de modalidades técnicas do regime eleitoral, não colocando em dúvida a tendência geral ao multipartidarismo". (DUVERGER, 1970, p.276).

Não há uma explicação consistente para a utilização da majority runoff, no Brasil, apenas nas cidades que excedem 200 mil eleitores. Jairo Nicolau (2012) informa que os dois turnos foram incluídos na eleição presidencial devido às baixas votações dos presidentes do período 1945-1964. No entanto, o referido pesquisador não encontra justificativas para que os constituintes de 1988 tenham optado pela adoção da fórmula de majority runoff, para o chefe do Executivo municipal, nas cidades com mais de 200 mil eleitores e não nas demais. Tanto na Constituição Federal ${ }^{9}$, quanto na Lei no 9.504 , de 30 de setembro de $1997^{10}$, que estabelece normas para as eleições, está ausente uma

\footnotetext{
${ }^{9}$ Art. 29, inciso II - eleição do Prefeito e do Vice-Prefeito realizada no primeiro domingo de outubro do ano anterior ao término do mandato dos que devam suceder, aplicadas as regras do art.77 no caso de Municípios com mais de duzentos mil eleitores.

Art. 77, inciso $3^{\circ}$ - Se nenhum candidato alcançar maioria absoluta na primeira votação, far-se-á nova eleição em até vinte dias após a proclamação do resultado, concorrendo os dois candidatos mais votados e considerando-se eleito aquele que obtiver a maioria dos votos válidos.
}

Art. 77, inciso $4^{\circ}$ - Se, antes de realizado o segundo turno, ocorrer morte, desistência ou impedimento legal de candidato, convocar-se-á, dentre os remanescentes, o de maior votação.

Art. 77, inciso $5^{0}$ - Se, na hipótese dos parágrafos anteriores, remanescer, em segundo lugar, mais de um candidato com a mesma votação, qualificar-se-á o mais idoso. Constituição da República Federativa do Brasil.

${ }^{10}$ Art. $3^{\circ}$ Será considerado eleito Prefeito o candidato que obtiver a maioria dos votos, não computados os em branco e os nulos.

Art. 30, inciso $\mathbf{1 0}^{\circ}$ - A eleição do Prefeito importará a do candidato a Vice-Prefeito com ele registrado.

Art. $\mathbf{3}^{\circ}$, inciso $\mathbf{2}^{\circ}$ - Nos Municípios com mais de duzentos mil eleitores, aplicar-se-ão as regras estabelecidas nos incisos $1^{\circ}$ a $3^{\circ}$ do artigo anterior. Lei no 9.504, de 30 de setembro de 1997.

As condições postas no artigo $2^{\circ}$ da Lei das Eleições são idênticas aos itens do artigo 77 da Constituição Federal visto na nota 8. 
justificativa para a exigência do segundo turno em apenas parte dos municípios brasileiro.

$\mathrm{Na}$ tabela 4, apresentamos as estatísticas acerca das localidades que utilizaram a regra de majority runoff, na eleição de 2008, aplicando o mesmo índice de candidatos efetivos utilizado anteriormente. Segundo a predição teórica de Duverger (1970), percebida antes como uma hipótese do que uma lei, o fenômeno tenderia a um aumento do número de competidores pela ausência dos efeitos mecânicos e psicológicos indutores da retirada de candidaturas no primeiro turno. Essa proliferação expressaria, por si, a existência de mais de dois partidos no sistema partidário. Qualquer dinâmica anti-dualista tenderia a reforçar a tendência de multipartidarismo (DUVERGER, 1970; DUVERGER, 2003).

Tabela 4. Competição eleitoral nos Municípios por Região com majority runoff nas eleições de primeiro turno de 2008 (\%)

\begin{tabular}{|c|c|c|c|c|c|c|}
\hline \multirow[b]{2}{*}{ majority runoff } & \multicolumn{5}{|c|}{ Regiões do Brasil } & \multirow[b]{2}{*}{$\begin{array}{c}\text { Média } \\
\text { nacional }\end{array}$} \\
\hline & $\begin{array}{c}\text { Região } \\
\text { Norte }\end{array}$ & $\begin{array}{l}\text { Região } \\
\text { Nordeste }\end{array}$ & $\begin{array}{c}\text { Região } \\
\text { Centro- } \\
\text { Oeste }\end{array}$ & $\begin{array}{l}\text { Região } \\
\text { Sudeste }\end{array}$ & $\begin{array}{c}\text { Região } \\
\text { Sul }\end{array}$ & \\
\hline Candidato Dominante & 0 & 7,8 & 20 & 4,8 & 0 & 5,2 \\
\hline Bicandidaturas & 33,3 & 46,1 & 40 & 61,9 & 36,4 & 52,0 \\
\hline Multicandidaturas & 66,7 & 46,1 & 40 & 33,3 & 63,6 & 42,8 \\
\hline Total & (6) & (13) & (5) & $(42)$ & (11) & 100,0 \\
\hline
\end{tabular}

Fonte: TSE, dados processados pelo autor. Cidades $\mathrm{N}=77$.

Os dados gerais, nacionais, são conclusivos em apontar que a competição eleitoral segue a tendência predita por Duverger (1970) acerca do aumento no número de competidores nas disputas por majority runoff, em comparação com a regra de plurality nas eleições de 2008. Apesar de os dados da região Sudeste desviarem um pouco da segunda lei de Duverger, e acabarem pesando para um resultado maior de bicandidaturas, isso não diminui a força explicativa da segunda lei de Duverger. Apenas mostra que os fatores mecânicos e psicológicos ocorrem, em certa medida, também em segundo turno.

Faz-se necessário comparar os resultados de 2008 com o pleito seguinte. No pleito de 2012, o recorte comparativo separou os 83 municípios com a possibilidade de segundo turno daquelas localidades, restantes, com turno único. Dentre as capitais estaduais, as únicas cidades que não preenchem o requisito para o segundo turno são Palmas, no Tocantins e Boa Vista, em Roraima.

$\mathrm{Na}$ tabela 5, observamos os resultados da competição eleitoral nas eleições de 2012 com majority runoff. Os resultados gerais não diferem da eleição de 2008 com a ampla predominância, dessa vez em todas as regiões, de 
multicandidaturas na disputa majoritária em dois turnos, caminhando no sentido visto por Duverger (1970) quanto ao aumento de candidaturas quando temos a possibilidade de um novo enfrentamento dos dois candidatos mais votados na disputa majoritária.

Tabela 5. Competição eleitoral nos Municípios por Região com majority runoff nas eleições de primeiro turno de $2012(\%)$

\begin{tabular}{|c|c|c|c|c|c|c|}
\hline \multirow[b]{2}{*}{ majority runoff } & \multicolumn{5}{|c|}{ Regiões do Brasil } & \multirow[b]{2}{*}{$\begin{array}{c}\text { Média } \\
\text { nacional }\end{array}$} \\
\hline & $\begin{array}{l}\text { Região } \\
\text { Norte }\end{array}$ & $\begin{array}{c}\text { Região } \\
\text { Nordeste }\end{array}$ & $\begin{array}{l}\text { Região } \\
\text { Centro- } \\
\text { Oeste }\end{array}$ & $\begin{array}{l}\text { Região } \\
\text { Sudeste }\end{array}$ & $\begin{array}{c}\text { Região } \\
\text { Sul }\end{array}$ & \\
\hline Candidato Dominante & 0 & 0 & 20 & 4,3 & 0 & 3,7 \\
\hline Bicandidaturas & 16,7 & 35,7 & 20 & 45,7 & 25 & 37,3 \\
\hline Multicandidaturas & 83,3 & 64,3 & 60 & 50 & 75 & 59,0 \\
\hline Total & (6) & (14) & (5) & $(46)$ & $(12)$ & 1000 \\
\hline
\end{tabular}

Fonte: TSE, dados processados pelo autor. Cidades $\mathrm{N}=83$.

Por último, algumas conclusões podem ser tiradas acerca da visão de Duverger (1970) sobre a fórmula eleitoral majoritária influenciar a competição eleitoral. A pergunta que surge desta pesquisa é: se retirássemos a fórmula de majority runoff (maioria absoluta) das eleições, teríamos uma diminuição dos candidatos, e por consequência, dos partidos em disputa? Os resultados em plurality apontam uma grande tendência de redução da competição pela ação dos fatores mecânicos e psicológicos pressionando o eleitor a recorrer ao voto estratégico/útil. A classe política e os proponentes de uma reforma política estes últimos, agentes da sociedade civil ou da opinião pública - têm na extinção da fórmula de majority runoff (maioria absoluta), mais permissiva para o lançamento de candidaturas, uma arma na redução dos partidos políticos. Consiste como tarefa futura averiguar se existe interesse nessa medida pelos atores que contestam o sistema eleitoral atual.

\section{Considerações Finais}

A escolha sobre a temática do sistema eleitoral visou compreender lacunas sobre seus efeitos por uma perspectiva abrangente de casos. O ângulo aqui adotado tem sido pouco explorado, afora casos monográficos, para o estudo da competição eleitoral que utiliza regras de maioria.

A pesquisa mostrou-se também importante para ampliar, em certa medida, o entendimento das reduzidas expectativas de vitória numa disputa eleitoral com regras que reduzem o número de candidatos efetivos. A ideia de excesso de siglas partidárias no contexto político prejudicando o discernimento do eleitor parece demasiada, pois nossos arranjos institucionais, vistos na maioria dos 
casos deste estudo por adotarem a fórmula de plurality (maioria simples), são fortes redutores de competição eleitoral.

O conhecimento da fórmula eleitoral utilizada nas disputas locais é um bom indicativo da dificuldade que um candidato irá enfrentar na campanha eleitoral. Apesar de o número de municípios com possibilidade de segundo turno ser inferior aos das cidades com turno único, a fórmula de majority runofff (maioria absoluta) ainda apresenta maiores oportunidades de sucesso para o lançamento de candidaturas. Esse é um dado que às vezes passa despercebido, já que partidos continuam lançando candidatos em condições mais desfavoráveis, ou seja, em municípios com plurality, sem atentar para os efeitos do sistema eleitoral.

Nossos resultados indicaram uma forte relação da primeira lei de Duverger sobre a fórmula eleitoral de plurality em turno único tender para bicandidaturas. De outro lado, os resultados para a segunda lei de Duverger, cuja fórmula eleitoral de majority runoff tenderia ao aumento dos candidatos efetivos na competição eleitoral, apresentou uma significativa correspondência com a predição teórica, acentuada na eleição de 2012 em comparação com a eleição de 2008.

Concluindo, esse estudo comparativo da fórmula eleitoral nos municípios brasileiros reforçou a validade de testar teorias mais abrangentes para compreensão de casos locais. Interessava verificar o quanto da produção teórica estrangeira resiste a refutações quando aplicada em casos com trajetórias distintas da europeia, como são os partidos brasileiros e dos demais países da América Latina. Mostrou-se nesta pesquisa que precisamos refinar as predições da teoria tradicional europeia já que ela não se aplica, inteiramente, para o caso nacional. Ainda assim, o argumento de Duverger é um bom preditor da estrutura de competição eleitoral. O contraste com um número maior de casos de representação de maioria, no futuro, pode dar contornos ainda mais nítidos sobre a influência da fórmula eleitoral na restrição à competição política.

\section{Referências Bibliográficas}

BRIQUET, J; SAWICKI, F. 1989. L'analyse localisée du politique. Politix. Vol. 2, no 7-8. Octobre-décembre, p.6-16.

BOIX, C. 2003. Democracy and Redistribution. New York: Cambridge University Press.

COLLOVALD, A; SAWICKI, F; HEURTIN, J. 1989. A propos des élections municipales. La définition $\mathrm{d}^{\prime}$ «une» élection. Politix. Vol. 2, $\mathrm{n}^{\circ} 7-8$. Octobre - décembre, p.139-150. 
COLOMER, J. 2003. Son los partidos los que eligen los sistemas electorales (o las leyes de Duverger cabeza abajo). Revista Española de Ciencia Política. No 9, Octubre, p.39-63.

COX, G. 1997. Making Votes Count: Strategic Coordination in the World's Electoral Systems. Cambridge: Cambridge University Press.

DOWNS, A. 1999. Uma Teoria Econômica da Democracia. São Paulo: Edusp.

DUVERGER, M. 1970. Os Partidos Políticos. Rio de Janeiro: Zahar.

DUVERGER, M. 2003. Duverger's Law: Forty years later. In: GROFMAN, B; LIJPHART, A. Electoral Laws and their Political Consequences. New York: Agathon Press.

KEMAN, H. 2008. Comparative research methods. In: CARAMANI, D. (Ed.). Comparative Politics. Oxford: Oxford University Press.

KIRCHHEIMER, O. 1966. The transformation of the Western European party systems. In: LaPALOMBARA, J \& WEINER, M (orgs.). Political parties and political development. New Jersey: Princeton University Press, p.177-200.

LAAKSO, M; TAAGEPERA, R. 1979. Effective Number of Parties: A measure with application to West Europe. Comparative Political Studies. N012, p. 3-27.

LIJPHART, A. 2008. Modelos de Democracia: desempenho e padrões de governo em 36 países. Rio de Janeiro: Ed. Civilização Brasileira.

LIMA JR, O. 1997. O Sistema Partidário Brasileiro. Rio de Janeiro: Editora Fundação Getúlio Vargas.

LIPSET, S; ROKKAN, S. 1967. Cleavage Structures, Party Systems, and Voter Alignments: An introduction. IN: Party Systems and Voter Alignments: Cross-National Perspectives. New York: Free Press.

MAINWARING, S. 2001. Sistemas Partidários em novas democracias - o caso do Brasil. Rio de Janeiro, Editora FGV.

MARENCO, A. 2012. Reformas Eleitorais na América Latina: grandes expectativas, poucos casos, resultados perversos. IN: Sociologias, Porto Alegre, ano 14, n³1, p.238-268, set/dez.

MORLINO, L. 1994. Problemas y opciones en la comparación. In: SARTORI, G (Orgs.). La Comparación en las Ciencias Sociales. Madrid: Alianza Editorial.

NICOLAU, J. 1996. Multipartidarismo e Democracia: um estudo sobre o sistema partidário brasileiro. Rio de Janeiro: Editora Fundação Getúlio Vargas.

NICOLAU, J. 1997. Notas sobre os quatro índices mais utilizados nos estudos eleitorais. In: LIMA JR, O. O Sistema Partidário Brasileiro. Rio de Janeiro: Editora Fundação Getúlio Vargas.

NICOLAU, J. 2012. Eleições no Brasil: do Império aos dias atuais. Rio de Janeiro: Editora Zahar.

NOHLEN, D. 1995. Sistemas electorales y partidos políticos. México: Fondo de Cultura Económica. 
PANEBIANCO, A. 1994. Comparacíon y explicacíon. In: SARTORI, G; MORLINO, L (Orgs.). La Comparacíon en las Ciencias Sociales. Madrid: Alianza Editorial.

RAE, D. 1971. The Political Consequences of Electoral Laws. New Haven: Yale University Press.

RIAL, J. 1988. Partidos políticos, leyes de Duverger y de Sartori. Revista Uruguaya de Ciencia Política. No 2, p.93-108.

SARTORI, G. 1994. Comparacíon y Método Comparativo. In: ; MORLINO, L (Orgs.). La Comparacíon en las Ciencias Sociales. Madrid: Alianza Editorial.

SAWICKI, F. 1988. Questions de recherche : pour une analyse locale des partis politiques. Politix. Vol. 1, no 2. Printemps, p.13-28, 1988.

SCHUMPETER, J. 1961. Capitalismo, Socialismo e Democracia. Rio de Janeiro: Editora Fundo de Cultura.

SHUGART, M; CAREY, J. 1992. Presidents and Assemblies: Constitutional Design and Electoral Dynamics. Cambridge: Cambridge University Press.

TAVARES, J. 1997. Rio Grande do Sul: o sistema partidário eleitoral e parlamentar. In: LIMA JR, O. O Sistema Partidário Brasileiro. Rio de Janeiro: Editora Fundação Getúlio Vargas.

\section{Documentos consultados}

BRASIL. 2012. Código eleitoral anotado e legislação complementar. Brasília: Tribunal Superior Eleitoral, Secretaria de Gestão da Informação. Disponível em:

<http://www.tse.jus.br/hotSites/CatalogoPublicacoes/pdf/codigo eleitoral 2012/TSE-Codigo-Eleitoral-2012-Web.pdf. > Acesso em 23 Dez 2013. 